\title{
Isolation of Protoplasts from Developing Barley Endosperm: a Tool for Transient Expression Studies
}

\author{
Isabel Diaz
}

Pilar Carbonero

\begin{abstract}
We have developed a method for the routine isolation of protoplasts from developing starchy endosperm of barley (Hordeum vulgare L.). Preplasmolysis of the intact endosperms, a low concentration of hydrolytic enzymes and gravity sedimentation before any centrifugation step, were crucial factors for a good preparation. Best yields were obtained early after pollination (8-13 days) or with mutants with low starch content. Transient expression of a reporter gene under the control of the 35s promoter, after polyethyleneglycol transfection of endosperm protoplasts, was of the same order as that found in coleoptile derived protoplasts. No significant difference in expression was found for a given tissue between $\mathrm{CV}$. Bomi and its mutant Ris $\phi 1508$. ABBREVIATIONS: 2,4D: 2,4 dichlorophenoxyacetic acid, dap: days after pollination, MS: Murashige and Skoog medium, pp: protoplasts, PEG: polyethylenglycol, GUS: $\beta-g l u c u r o n i d a s e$,

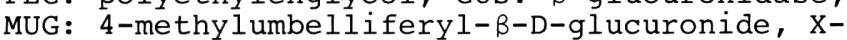
gluc: 5-bromo-4 chloro-3 indolyl glucuronide.
\end{abstract}

\section{INTRODUCTION}

In cereal species that are still recalcitrant to stable transformation and regeneration, transient expression in isolated protoplasts is a useful tool for the study of gene expression and regulation.

A number of reports have recently appeared concerning the isolation of barley protoplasts from different cell types: i) aleurone cells (Jacobsen et al. 1985, Lee et al. 1989, Olsen et al. 1990, Salmenkallio et al. 1990, Potter et al. 1991, Gopalakrishnan et al. 1991), ii) leaf mesophyll cells (Loveys and Robinson 1987, Owen 1987, Salmenkallio et al. 1990), iii) scutellar epithelium (Salmenkallio et al. 1990) and iv) cell cultures (Lührs and Lörz 1988, Jähne et al. 1991, Lazzeri et al. 1991, Kaneko et al. 1991). However, metabolically active protoplasts from starchy endosperm have been found to be difficult to prepare on a routine basis. Because of the high number of endosperm-specific barley genes so far characterized, the development of a reliable procedure to prepare protoplasts from this tissue can be considered as an important objective. With the exception of recent experiments by Lee et al. (1991), which appeared when work reported here was in its final stages, no viable method for the preparation of barley endosperm protoplasts was available. In the present study, we describe a reproducible procedure to obtain protoplasts from developing endosperm in high yield, with which transient expression levels can be achieved that are of the same order as those obtained with coleoptile protoplasts.

\section{MATERIALS AND METHODS}

Plant material. Barley (Hordeum vulgare L.) CV. Bomi and its mutant Ris $\phi 1508$ were used throughout this study.

Isolation of protoplasts from developing endosperms. Barley seeds germinated in the dark were vernalized at $4{ }^{\circ} \mathrm{C}$ during 4 weeks under dim fluorescent light. Plants were grown in a greenhouse under a $16 \mathrm{~h}$ photoperiod.

Ears were tagged at anthesis and harvested at different times after pollination.

Developing kernels were surface sterilised by immersion in $10 \%(\mathrm{v} / \mathrm{v})$ "Domestos" (Lever, Spain) for $30 \mathrm{~min}$. After several washes in sterile tap water, endosperms were isolated under aseptic conditions and plasmolysed for $1 \mathrm{~h}$ in CPW salts (Power and Chapman 1985) with $11 \%(\mathrm{w} / \mathrm{v})$ mannitol as osmoticum (CPW11M). After this treatment, endosperms were incubated in the dark for $14 \mathrm{~h}$ in the same medium containing $0.4 \%(\mathrm{w} / \mathrm{v})$ Cellulase Onozuka RS. The digested tissue was then filtered through a nylon sieve $(250 \mu \mathrm{m}$ pore size), gently washed with CPW11M medium and the filtrate allowed to sediment for 15 min. Supernatants were removed and centrifugated twice at $40 \mathrm{~g}$ for 3 min and the two pellets combined with the initial sediment in CPW11M. Protoplasts were purified by centrifugation $(60 \mathrm{~g} 5 \mathrm{~min})$ onto a $2 \mathrm{ml} 50 \%$ Percoll cushion (1 volume Percoll: 1 volume $2 \times \mathrm{CPW}$ salts containing $19 \%(\mathrm{w} / \mathrm{v})$ mannitol).

The protoplast band was carefully collected with a sterile Pasteur pipette at the Percoll interface and resuspended in MSL medium (MS base medium containing $9 \%(\mathrm{w} / \mathrm{v})$ mannitol, $3 \%(\mathrm{w} / \mathrm{v})$ sucrose and $30 \mathrm{ml} / \mathrm{l}$ coconut water, $\mathrm{pH} 5.8)$. After centrifugation (40 g $3 \mathrm{~min})$, the pellet was resuspended in the same medium at a final density of $10^{5} \mathrm{pp} / \mathrm{ml}$.

Isolation of protoplasts from coleoptiles. Dry seeds treated with $35 \%$ (v/v) "Domestos" were germinated for $7 \mathrm{~d}$ at $27^{\circ} \mathrm{C}$ under constant 


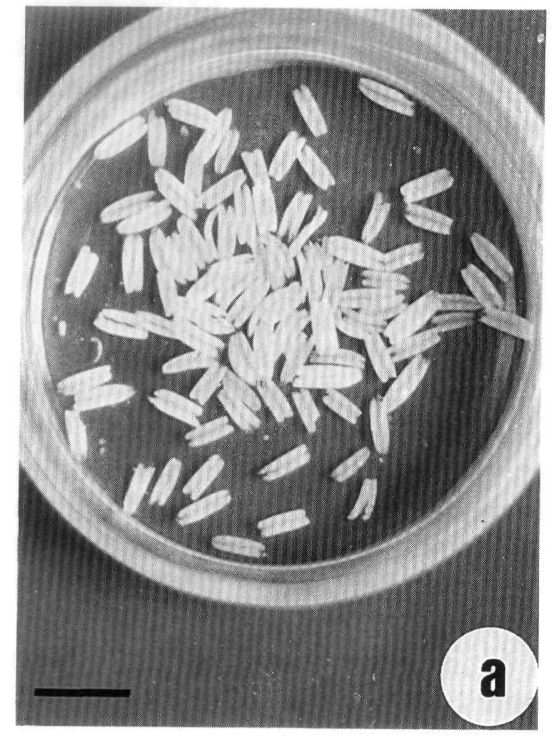

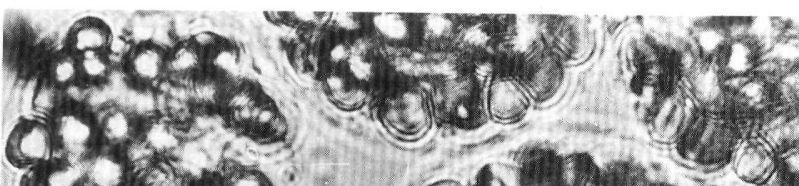

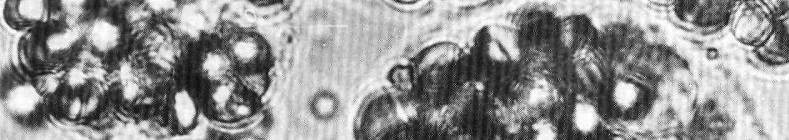
cor. $640 \%$

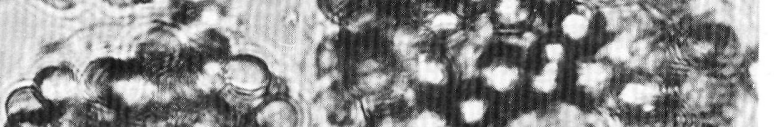
efor. $30 \%$ ?

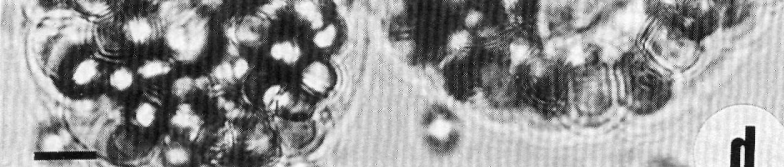

acea witry

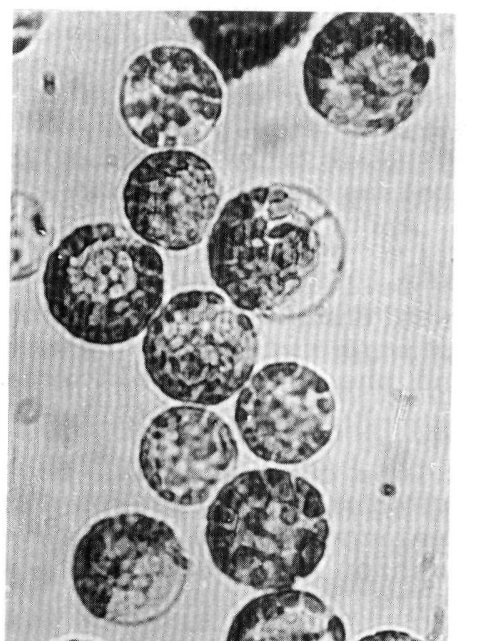

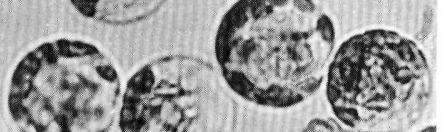
2- 6 a $^{3}$ ।

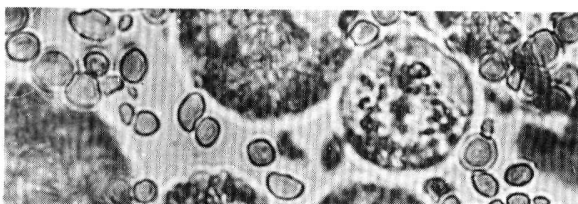
3. 5 (4) (9) 0 0ल 7. na 00 o

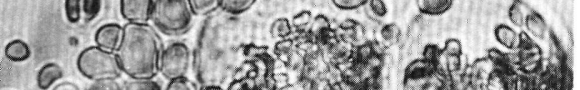

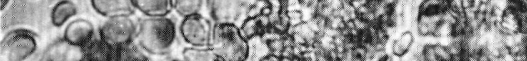

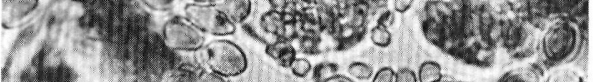

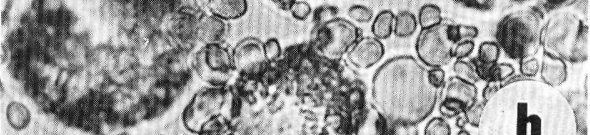
año 0 in

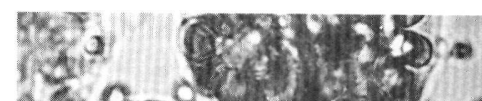
of (6)

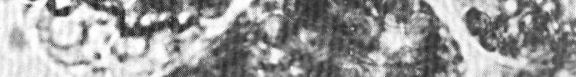

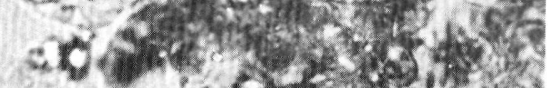

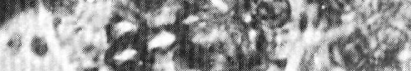

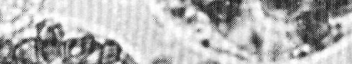

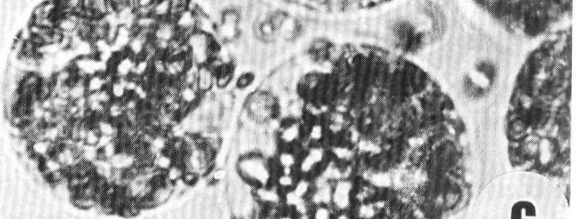

bifacis, C

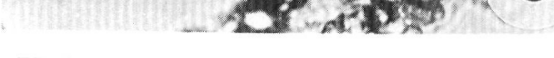

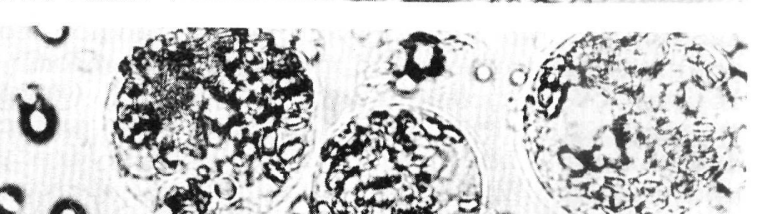

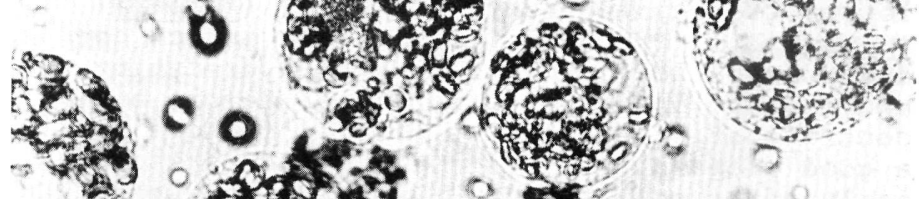
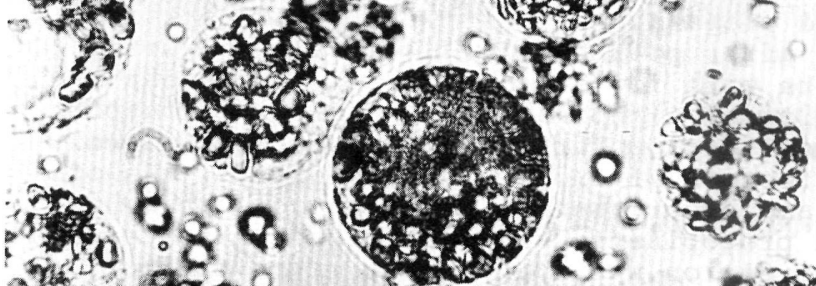
mo ho?

(1) $1 \frac{2}{20}$
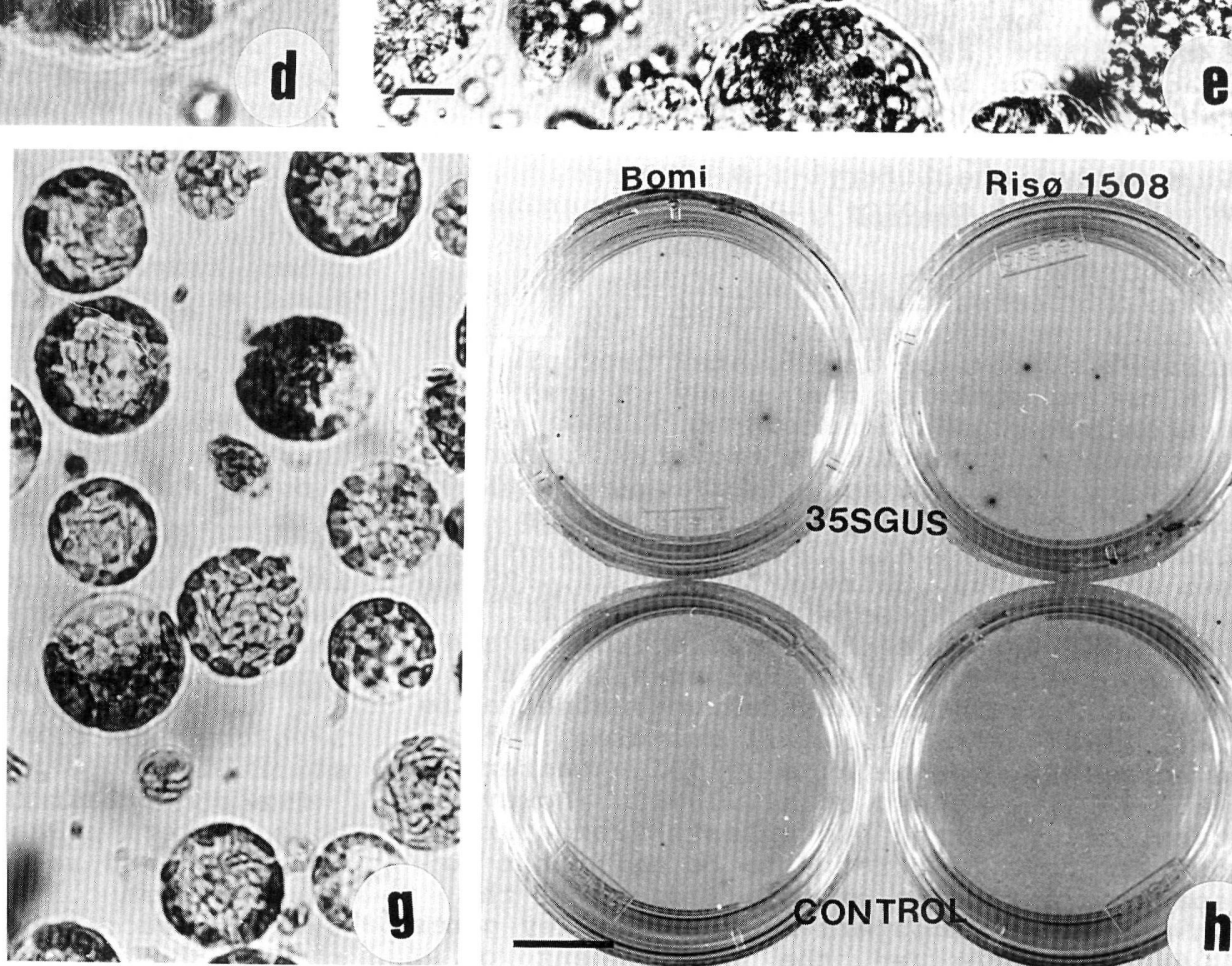

Figure 1. Protoplasts from barley endosperms and coleoptiles and "in situ" Gus activity

endosperm protoplasts of Bomi prior to purifing starchy endosperms 8-13 dap (bar: $1 \mathrm{~cm}$ ). b: protoplasts of Bomi (bars: $10 \mu \mathrm{m}$ and $5 \mu \mathrm{m}$ ) (bar: $10 \mu \mathrm{m}$ ) $\mathrm{f}, \mathrm{g}$ : (bis $\phi 1508$ (bar: $10 \mu \mathrm{m})$. h: detection 
illumination. Small coleoptile pieces (0.5$2 \mathrm{~mm}$ ) after plasmolysis were digested with $2 \%$ $(\mathrm{w} / \mathrm{v})$ Cellulase Onozuka RS and $0.5 \%(\mathrm{w} / \mathrm{v})$ Macerozyme R10. After filtration $(500$ and $64 \mathrm{\mu m}$ pore size sieves) and centrifugation at $80 \mathrm{~g} \times 5 \mathrm{~min}$, the pellet was resuspended in CPW21s medium (CPW salts with $21 \%$ sucrose) and the floating protoplast band diluted in MSL medium containing $1 \mathrm{mg} / \mathrm{l} \mathrm{2,4D}$ and 20 $\mathrm{ml} / \mathrm{l}$ coconut water.

PEG-mediated DNA transfer into protoplasts. Plasmid p35SGUS harboured a chimeric gene made of the 35S promoter from the Cauliflower Mosaic Virus fused to the coding region of the $\beta-$ glucuronidase gene and the $3^{\prime}$ noncoding region of the nopaline synthase gene.

The procedure for plasmid uptake into protoplasts was mediated by PEG and was adapted from Negrutiu et al. (1987). Aliquots of 500 $\mu l$, containing $0.5-2 \times 10^{6} \mathrm{pp} / \mathrm{ml}$, were incubated with $30 \mu \mathrm{g}$ of plasmid DNA and $75 \mu \mathrm{g}$ of salmon sperm DNA as a carrier. A solution of $40 \%(\mathrm{w} / \mathrm{V})$ PEG3400 containing $0.4 \mathrm{M}$ mannitol and $0.1 \mathrm{M} \mathrm{Ca}\left(\mathrm{NO}_{3}\right)_{2}(\mathrm{pH} 8)$ was added to a final concentration of $15 \%$ PEG and very gently mixed. After $20 \mathrm{~min}$ at $25^{\circ} \mathrm{C}$, the protoplasts were slowly diluted in the solution described by Krens et al. (1982), centrifugated and the resuspended pellet incubated at $27^{\circ} \mathrm{C}$ for $20 \mathrm{~h}$. Transient expression assays. Approximately $20 \mathrm{~h}$ after DNA delivery, protoplasts were collected by centrifugation and GUS activity measured using MUG as a substrate by the fluorometric assay of Jefferson (1987). Total cellular protein was determined using the BioRad kit. A Neubauer chamber was used to count protoplasts.

"In situ" detection of GUS was carried out after $20 \mathrm{~h}$ in culture by mixing a $500 \mu \mathrm{l}$ aliquot from the protoplast culture with an equal volume of the melted immobilization medium described by Denecke et al. (1989). The immobilized cultures, at a final plating density of $10^{4} \mathrm{pp} / \mathrm{ml}$, were incubated in the dark at $37^{\circ} \mathrm{C}$ for $16 \mathrm{~h}$ and then, individual blue sports counted visually.

\section{RESULTS AND DISCUSSION}

Protoplast isolation from immature starchy endosperms and coleoptiles of barley. The procedure described here allows the routine isolation of metabolically active protoplasts from starchy endosperms with little debris contamination (Fig. $1 \mathrm{a}, \mathrm{b}, \mathrm{c}, \mathrm{d}, \mathrm{e}$ ). Three improvements seem to be essential for the success of the procedure: i) Preplasmolysis of the intact endosperms in CPWI1M medium, which allows a good separation of the cell wall and cytoplasmic membrane before digestion with cellulase. ii) A gravity sedimentation and two low centrifugation steps to concentrate the protoplasts after the hydrolysis of the cell walls. iii) Centrifugation onto the Percoll cushion that separates the cellular debris and starch granules with little damage to endosperm protoplasts. In contrast to the procedure of Lee et al. (1991), pectinase was omitted and a much lower concentration of cellulase was used, although longer digestion times were necessary.

Endosperms from early stages of development ( 8 to 13 dap) were a more suitable starting material than those collected at later stages. No viable protoplasts could be ontained after 20 dap. The protoplast yield was about $20 \%$ higher in barley mutant Ris $\phi 1508$ than in its corresponding wild type $\mathrm{cv}$.Bomi (Table 1). The lower yield of endosperm protoplasts obtained at later stages of development is likely to be due to the damaging effect of starch granules upon the delicate membrane of the protoplasts throughout the different manipulations. Lower starch concentration is present in the mutant Ris $\phi 1508$ with respect to its wild type (Doll 1984). This circumstance might explain the significant increase in yield and viability observed for the endosperm protoplasts from the mutant, a difference that does not occur in the case of the coleoptile protoplasts (Table 1). A decrease in yield and viability in endosperm protoplasts as related to starch increase has also been reported in wheat (Entwistle et al. 1988; Keeling et al. 1989) and in maize (Schwall and Feix 1988). Although protoplasts derived from endosperm were consistently larger (25 to $45 \mu \mathrm{m}$ in diameter) than those derived from coleoptile (15 to $25 \mu \mathrm{m})$, no difference in shape or in size was found, for a given tissue, between Bomi and Ris $\phi 1508$ (Fig. 1 c,e,f,g,). Endosperm protoplasts remained viable in culture medium for up to 3-4 days. During this time, the number and size of starch granules increased considerably but neither changes in shape nor cellular divisions occurred.

Coleoptile protoplasts remained viable in culture for several days and changes in shape indicating cell wall synthesis were evident. Chloroplasts moved around the nuclei as a prelude to meiosis, but first division only occurred when molten agarose was added to the culture medium. Similarly, Hähne et al.

Table 1. Protoplasts yield and viability before and after DNA transfection in barley

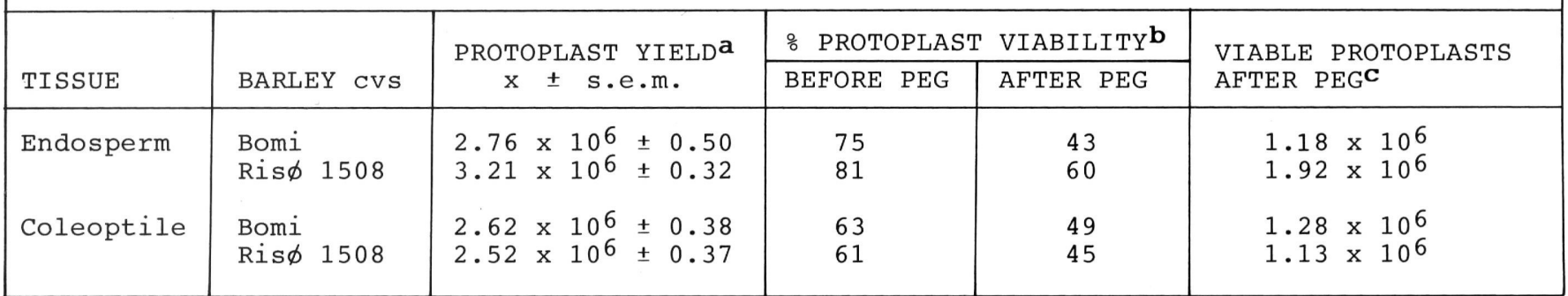

aprotoplast yield for endosperms is referred to 100 developing kernels (mean of 4 different experiments). Yield for coleoptile protoplasts is referred to 1 gram of fresh tissue.

brotoplast viabilities were monitored before and after PEG induced DNA transfection and expressed as number of protoplasts which excluded the Evans Blue dye per 100 protoplasts.

coverall yield of viable protoplasts after transfection $(\mathbf{c}=\mathbf{a} \mathbf{x} \mathbf{b})$. 
Bomi

\section{Ris $\phi 1508$}
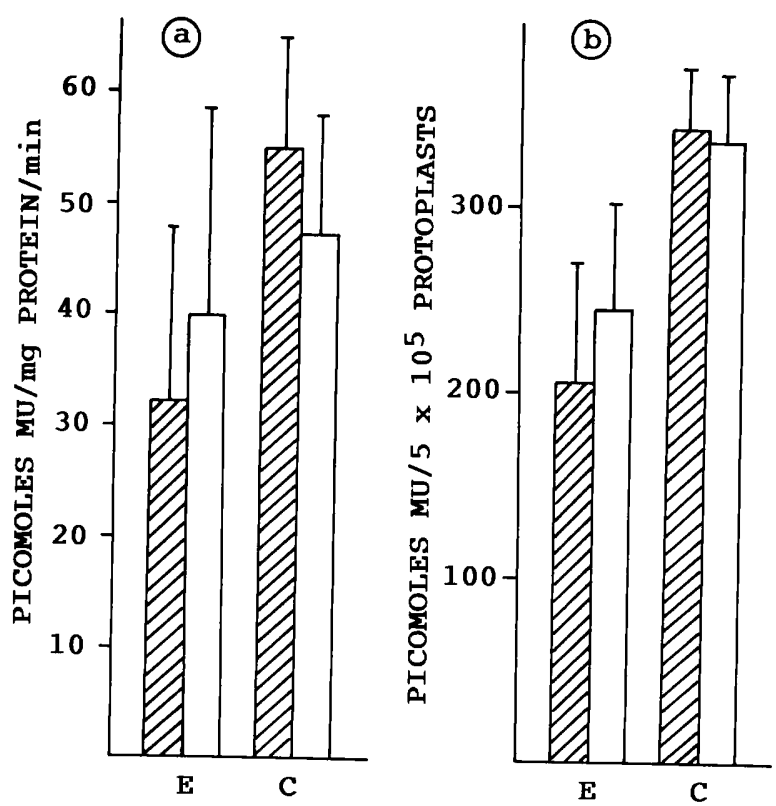

Figura 2. GUS expression measured $20 \mathrm{~h}$ after PEG treatment in protoplasts from endosperms and coleoptiles of barley. a) GUS activity expressed as pmoles MU per mg total protein per min. b) GUS activity expressed as pmoles MU per $5 \times 10^{5}$ viable protoplasts. $\mathrm{E}=$ endosperm; $\mathrm{C}=$ coleoptile; $\mathrm{MU}=4$-methylumbelliferone.

(1991) observed divisions in their oat protoplast preparations when plating in a medium solidified with alginate.

Transfection of barley protoplasts and transient expression studies. Transient expression levels obtained under the control of the $35 \mathrm{~S}$ promoter in endosperm protoplasts were of the same order as those observed for coleoptile protoplasts (Fig. 2). In contrast with the suggestion of Lee et al. (1991), no significant difference in the levels of transient expression were found between Bomi and Ris $\phi 1508$ when the GUS activity was referred to the number of viable protoplasts or when it was expressed per mg of total protein (Fig. $2 \mathrm{a}, \mathrm{b})$. Again, the lower starch content of the mutant Ris $\phi 1508$ might explain the higher yield of viable protoplasts after PEG-mediated DNA uptake (Table 1), but this does not mean that the protoplasts are more active metabolically.

The actual proportion of GUS-expressing protoplasts could not be determined in liquid medium because of the diffusibility of the reaction product ( $\mathrm{X}-\mathrm{gluc}$ ), but an estimation was obtained by staining "in situ" after immobilization (Fig. 1h). The number of blue spots was of the same order in Ris $\phi 1508$ than in Bomi, in agreement with the fluorometric
Several barley endosperm specific genes have been recently cloned in our $l a b$ and their promoters used in transient expression studies in the endosperm protoplast system. The potential of this tool has thus been fully
assessed.

\section{ACKNOWLEDGEMENTS}

We thank Dr. M.J. Carmona for providing plasmid p35sGUS, and L. Lamoneda and J. Garcia for assistance in the preparation of this manuscript. We also thank Prof. F. GarciaOlmedo for advice and helpful discussions throughout this work. Financial support was by grant DGCYT PB89-0190 for Ministerio de Educación y Ciencia, and CICYT Bio88-0216 from Comisión Interministerial de Ciencia $y$ Tecnología (Spain).

\section{REFERENCES}

Denecke J, Gossele V, Botterman J, Cornelissen M (1989) Meth Mol Cell Biol 1:19-27

Doll H (1984) Philos Trans Royal Soc London Ser B $304: 380$

Entwistle G, Tyson RH, Rees T (1988) Phytochemistry 27:993-996

Gopalakrishnan B, Sonthayanon B, Rahmatullah R, Muthukrishnan S (1991) Plant Mol Biol $16: 463-467$

Hähne B, Fleck J, Hähne G (1991) Physiol Plant 82:A7

Jacobsen JV, Zwar JA, Chandler PM (1985) Planta $163: 430-438$

Jähne A, Lazzeri PA, Lörz H (1991) Plant Cell Rep 10:1-6

Jefferson RA (1987) Plant Mol Biol Rep 5:387405

Kaneko T, Kuroda H, Hirota N, Kisninami I, Kimura N, Ito K (1991) Proc 6th Intern Barley Genet Symp, Helsingborg, Sweden. Munksgaard International Publishers, Denmark pp 231-233

Keeling PL, Baird S, Tyson RH (1989) Plant Sci $65: 55-62$

Krens FA, Molendijk L, Wullems GJ, Schilperoot RA (1982) Nature 296:72-74

Lazzeri PA, Biettschneider R, Lührs R, Lörz H (1991) Theor Appl Genet 81:437-444

Lee BT, Murdoch K, Topping J, Kreis M, Jones MGK (1989) Plant Mol Biol 13:21-29

Lee BT, Murdoch K, Topping J, Jones MGK, Kreis M (1991) Plant Sci 78:237-246

Loveys BR, Robinson SP (1987) Plant Sci 49: $23-30$

Lührs R, Lörz H (1988) Planta 175:71-81

Negrutiu I, Shillito R, Potrykus I, Biasini G, Sala F (1987) Plant Mol Biol 8:363-373

Olsen FL, Stilling B, Mundy J (1990) Abstract VII Inter Congr Plant Tiss and Cell Cult. IAPTC (ed) Amsterdam, Holland pp 71

Owen JH (1987) J Plant Physiol 130:385-393

Potter R, Melby $T$, Klemsdal S, Aalan R, L, $82: A 32$

Power JB, Chapman JV (1985) In: Dixon RA (ed) Plant Cell Culture. IRL Press, Oxford, Washington DC pp 37-66

Salmenkallio M, Hannus $R$, Teeri $T H$, Kauppinen $V$ (1990) Plant Cell Rep 9:352-355

Schwall M, Feix G (1988) Plant Sci 56:161-166 